\title{
SUMBER OTORITAS PELAKSANAAN SUPERVISI PENDIDIKAN
}

\author{
Hartono \\ Universitas Islam Negeri (UIN) Mataram, Indonesia \\ Email: hhartono128@gmail.com
}

\begin{tabular}{ll}
\hline INFO ARTIKEL & ABSTRAK \\
\hline Diterima & Artikel ini bertujuan untuk menganalisis bagaimana sumber kewenangan \\
22 Juni 2020 & untuk pelaksanaan pengawasan. Dilihat dari kualitas pendidikan di \\
Direvisi & Indonesia, yang saat ini masih jauh tertinggal dari negara lain, baik di Asia \\
6 Juli 2020 & maupun di negara-negara Eropa. sebagai hasil dari sumber daya manusia \\
Disetujui & yang tidak memadai, serta teknologi dan ilmu pengetahuan yang tidak \\
10 Juli 2020 & merata di Indonesia. Kepala sekolah dan pendidik yang belum \\
Kata Kunci: & melaksanakan tugasnya untuk pelaksanaan pembelajaran dengan baik. \\
Pengawasan, & Kepala sekolah yang tidak pandai mengawasi guru pengajar dan guru yang \\
kepala sekolah & hanya bertugas mengajar, padahal merupakan tugas pendidik untuk \\
& membentuk karakter siswa. Pada artikel ini, kita akan membahas \\
& bagaimana melakukan pengawasan, upaya peningkatan pengawasan, serta \\
& peran pengawas bagi pengawas dan kepala sekolah sebagai sumber \\
& kewenangan pelaksanaan pengawasan. Pengawasan merupakan bantuan \\
& kepada pendidik dalam memperbaiki situasi pembelajaran, pengawasan \\
& pendidikan meliputi pengawasan pembelajaran dan komponen \\
& pendukungnya. Kegiatan pengawasan dilakukan melalui berbagai proses \\
pemecahan masalah pembelajaran.
\end{tabular}

\section{ABSTRACT}

This article aims to analyze how the source of authority for the implementation of supervision is. Judging from the quality of education in Indonesia, which is currently still far behind other countries, both in Asia and in European countries. as a result of inadequate human resources, as well as technology and science that is not evenly distributed in Indonesia. Principals and educators who have not carried out their duties for the implementation of learning properly. Principals who are not good at supervising teaching teachers and teachers who are only in charge of teaching, even though it is an educator's job to shape the character of students. In this article, we will discuss how to carry out supervision, efforts to improve supervision, as well as the role of supervisors for supervisors and school principals as sources of authority for implementing supervision. Supervision is an aid to educators in Keywords: improving the learning situation, educational supervision includes Authority, supervision of learning and its supporting components. Supervision Supervision, activities are carried out through various learning problem solving principal. processes.

\section{Pendahuluan}

Pendidikan di Indonesia pada saat ini belum mencapai kondisi yang diharapkan, apabila dibandingkan dengan Negara-negara lain yang pendidikannya jauh lebih baik daripada Indonesia. Kualitas dan mutu pendidikan yang rendah serta tujuan pembelajaran yang belum tercapai seperti 
yang diharapkan, dikarenakan perkembangan tehnologi dan ilmu pengetahuan yang belum merata ke seluruh wilayah Indonesia. Untuk tercapainya pendidikan yang berkualitas diperlukan pendidik yang professional,berkualitas dan memenuhi kompetensi-kompetensi yang dipersyaratkan.

Kemampuan professional yang harus dimiliki seorang guru menurut Glasser "adalah (1) menguasai bahan pelajaran,(2)kemampuan mendignosa tingkah laku siswa, (3) kemampuan melaksanakan proses pengajaran,(4) kkemampuan mengukur proses belajar siswa (Husni, 2019).

Dalam rangka pelaksanaan program supervisi maka harus mencakup semua komponen yang terkait dan mempengaruhi terhadap keberhasilan program supervisi. Keberhasilan tersebut dilihat dari komponen perencanaan, implementasi, evaluasi serta tindak lanjut supervisi. Kepala Sekolah dalam melaksanakan tugas dan tanggung jawabnya sebagai supervisor secara efektif, maka harus memiliki kompetensi sebagai kepala sekolah sebagaimana termuat dalam peraturan dan perundang-undangan yang mengaturnya. Dalam menjalankan amanah tanggung jawabnya, seorang Kepala Sekolah tidak terlepas dari kesalahan dan kekeliruan. Oleh karena itu diperlukan adanya pengawas yang mengontrol dan meluruskan kembali kesalahan dan kekliruan tersebut. Sehingga dengan demikian akan tercipta suasana pembelajaran yang kondusif, agar tujuan dari pembelajaran dapat terwujud.

Kepala sekolah dalam pelaksanaan supervisi bukan hanya menilai kinerja seorang guru saja tetapi semua kegiatan yang berhubungan dengan proses pembelajaran (Husni, 2019). Supervisi dalam dunia pendidikan menjadi sangat penting dilaksanakan karena berpengaruh terhadap kinerja guru sekaligus pada hasil pembelajaran (Fitri, 2020). Secara umum fungsi supervisi pendidikan adalah salah satu mekanisme untuk meningkatkan kemampuan profesional dalam upaya mewujudkan proses belajar peserta didik yang lebih baik melalui mengajar yang lebih baik pula. Secara khusus berfungsi pula untuk mengkoordinasi semua usaha sekolah, memperluas pengalaman guru, mendorong usaha-usaha pembelajaran kreatif, memberikan penilaian secara terus menerus, dan memberikan pengetahuan serta keterampilan kepada guru. Sehingga supervisi pendidikan adalah pembinaan yang berupa bimbingan atau tuntunan ke arah perbaikan situasi pendidikan pada umumnya dan peningkatan mutu mengajar dan belajar dan belajar pada khususnya (Fitri, 2020). Fungsi dasar dari supervisi adalah untuk mempervaiki situasi belajar mengajar disekolah agar lebih baik. Supervisi terhadap proses belajar mengajar, merupakan salah satu bentuk aktivitas yang direncanakan untuk membantu para guru dalam melakukan pekerjaan yang direncanakan untuk membantu para guru dalam melakukan pekerjaan mereka secara efektif (Hendriawati, 2019). Melalui kegiatan supervisi, guru mendapatkan arahan, bimbingan dan pembinaan dari pengawas sekolah untuk berbagai kendala yang dialami dalam melaksanakan tugasnya di sekolah (Messi et al., 2018).

Fungsi pengawas adalah hanya sebagai mitra kepala sekolah dan guru untuk mencapai tujuan sekolah. Dengan kata lain, pengawas berperan sebagai supervisi manajerial dan supervisor akademik. Jika terdapat peran yang tidak 
dilaksanakan, maka sekolah mengalami kendala dalam pengembangan dalam penyelenggaraannya (Musdalipa et al., 2021).

\section{Metode Penelitian}

Penelitian ini menggunakan studi dokumen atas hasil-hasil penelitian sebelumnya. Pengumpulan data dalam penelitian ini dilakukan dengan menelusuri jurnal pada beberapa media elektronik seperti digital library dan internet, Penelusuran jurnal dilakukan melalui Google Cendekia.

\section{Hasil dan Pembahasan}

A. Landasan yuridis Otoritas Supervisi Mutu pendidikan di Indonesia dari tahun ke tahun terus menjadi sorotan baik dari kalangan akademisi maupun kalangan pemerhati pendidikan. Sejak diberlakukannya Keputusan Menteri Pendidikan dan kebudayaan, RI. Nomor: 0134/1977, yang menyebutkan siapa saja yang berhak disebut supervisor di sekolah, yaitu kepala sekolah, penilik sekolah untuk tingkat kecamatan, dan para pengawas di tingkat kabupaten/ Kota dan di dalam PP Nomor 38/Tahun 1992, terdapat perubahan penggunaan istilah pengawas dan penilik. Istilah pengawas dikhususkan untuk supervisor pendidikan di sekolah sedangkan penilik khusus untuk pendidikan luar sekolah.dan didalam Keputusan Menteri Pendidikan Nasional Republik Indonesai Nomor 097/U/2002 tentang Pedoman Pengawasan Pendidikan (Slameto, 2016).

Supervisi merupakan kegiatan yang kompleks, oleh karena itu harus dilakukan oleh orang-orang profesional. Di dalam pengetian tersebut tergambar bahwa seorang supervisor harus orang yang memiliki jabatan resmi yang memiliki kewenangan atau otoritas dalam pengawasan. Pengawasan dalam artian ini berarti orang yang diangkat oleh pemerintah untuk mengawasi satuan pendidikan atau lembaga pendidikan. Supervisor/pengawas dalam hal ini berarti orang yang berada atau bertugas diluar satuan pendidikan yang mengawasi terhadap pelaksanaan proses belajarmengajar di sekolah. Pengawas ini melakukan fungsi dan tugasnya kepada orang-orang yang disupervisi mencakup kepala sekolah dan guru-guru di sekolah (Slameto, 2016).

Unsur utama dari pelaksanaan supervisi pendidikan yaitu pembinaan yang dilakukan pengawas sekolah kepada semua guru di sekolah binaannya tersebut. Melalui kegiatan supervisi, guru mendapatkan arahan, bimbingan dan pembinaan dari pengawas sekolah untuk berbagai kendala yang dialami dalam melaksanakan tugasnya di sekolah (Messi et al., 2018).

B. Peran Sumber Otoritas pelaksanaan supervisi

1 Pelaksanaan Supervisi oleh Kepala sekolah

Menurut (Sabandi, 2013) perkembangan supervisi pendidikan berkembang seiring dengan perkembangan ilmu pengetahuan, teknologi, serta sosial ekonomi dan budaya masyarakat. Supervisi bergerak dari berbentuk inspeksi dimana otoritas lebih didominasi oleh supervisor, berkembang dalam bentuk kolaborasi antara supervisor dan guru bersama berinisiatif dan bertanggungjawab dalam meningkatkan kualitas pembelajaran, serta menumbuhkan budaya belajar pada guru untuk selalu meningkatkan kompetensinya. Wewenang supervisor adalah melaksanakan koreksi, memperbaiki dan membina proses belajar mengajar bersama guru, sehingga proses itu mencapai hasil yang maksimal (Sabandi, 2013).

Menurut Tim Dosen Administrasi Pendidikan (2014) proses supervisi 
merupakan rangkaian yang dilaksanakan ketika supervisi dilaksanakan. Secara umum proses pelaksanaan supervisi dilaksanakan melalui tiga tahap yaitu perencanaan, pelaksanaan dan evaluasi (Hendriawati, 2019).

a) Perencanaan

Kegiatan perencanaan mengacu pada kegiatan identifikasi permasalahan, yaitu mengidentifikasi aspek-aspek yang perlu disupervisi. Identifikasi dilaksanakan dengan menganalisis kelebihan, kekurangan, peluang dan ancaman dari aspek kegiatan pembelajaran yang dilaksanakan oleh guru agar supervisi lebih efektif dan tepat sasaran. Langkah-langkah yang dilakukan dalam perencanaan supervisi adalah (1) mengumpulkan data melalui kunjungan kelas, pertemuan pribadi, rapat staf; (2) mengolah data dengan melakukan koreksi kebenaran terhadap data yang dikumpulkan;

mengklasifikasi data sesuai dengan bidang permasalahan; (4) menarik kesimpulan tentang permasalahan sasaran sesuai dengan keadaan yang sebenarnya; dan (5) menetapkan teknik yang tepat untuk memperbaiki atau meningkatkan profesional guru.

b) Pelaksanaan

Kegiatan pelaksanaan merupakan kegiatan nyata yang dilakukan untuk memperbaiki atau meningkatkan kemampuan guru. Kegiatan pelaksanaan merupakan kegiatan pemberian bantuan dari supervisor kepada guru agar pelaksanaan supervisi dapat efektif sesuai dengan perencanaan yang ditetapkan. Supervisi tidak berhenti pada selesainya pemberian bantuan dan terlaksananya teknik supervisi melainkan ada follow up untuk melihat keberhasilan proses dan hasil pelaksanaan supervisi, sehingga kegiatan evaluasi perludilaksanakan.

c) Evaluasi
Kegiatan evaluasi merupakan kegiatan untuk menelaah keberhasilan proses dan hasil pelaksanaan supervisi. Evaluasi dilaksanakan secara komprehensif. Sasaran evaluasi supervisi ditujukan kepada semua orang yang terlibat dalam proses pelaksanaan supervisi. Hasil dari evaluasi supervisi akan dijadikan pedoman untuk menyusun program perencanaan berikutnya. Namun, banyak juga ahli supervisi yang mengemukakan tiga langkah supervisi yaitu pertemuan pendahuluan, observasi guru yang sedang mengajar dan pertemuan balikan (Kristiawan et al., 2019).

Sebagai supervisor kepala sekolah harus juga memperhatikan prinsip-prinsip diantaranya :

1) Hubungan konsultatif, kolegial, dan bukan hirarkhi.

2) Dilaksanakan secara demokratis.

3) Berpusat pada tenaga kependidikan (guru).

4) Dilakukan berdasarkan kebutuhan tenaga kependidikan.

5) Merupakan bantuan profesional dan dapat juga dilakukan secara efektif antara lain melakukan diskusi kelompok, kunjungan kelas atau pembicaraan individual, dan simulasi pembelajaran (Amanda et al., 2017).

2 Pelaksanaan supervisi oleh Pengawas sekolah

Standar mutu pengawas yang telah ditetapkan oleh Direktorat Jenderal Peningkatan Mutu Pendidik dan Tenaga Kependidikan Direktorat Tenaga Kependidikan Departemen Pendidikan Nasional (Sudjana, 2006) bahwa pengawas sekolah berfungsi sebagai supervisor baik supervisor akademik maupun supervisor manajerial. Sebagai supervisor akademik, pengawas sekolah berkewajiban untuk membantu kemampuan profesional guru agar guru dapat meningkatkan mutu proses 
pembelajaran. Sedangkan sebagai supervisor manajerial, pengawas berkewajiban membantu kepala sekolah agar mencapai sekolah yang efektif (Slameto, 2016).

Supervisi termasuk kegiatan yang kompleks, dalam artian bahwa bahwa seorang supervisor harus orang yang memiliki jabatan resmi yang memiliki kewenangan dan atau ot dalam pengawasan. Menurut (S 4 2010) dalam (Messi et al., 2018) mengatakan bahwa pengawas sekolah merupakan tenaga kependidikan profesional yang diberi tanggung jawab, tugas, dan wewenang secara penuh oleh pejabat yang berwenang untuk melakukan pembinaan dan pengawasan dalam bidang akademik maupun bidang manajerial (Messi et al., 2018).

Sebagai salah satu sumber otoritas pelaksanaan supervisi oleh pengawas sekolah maka pengawas/supervisor memegang peranan yang sangat strategis dalam meningkatkan kualitas pembelajaran. Supervisi atau pembinaan tenaga pendidik oleh pengawas ini lebih menekankan pada pembinaan profesioanalisme yaitu pembinaan yang lebih ditujukan dalam upaya memperbaiki dan meningkatkan kemampuan profesionalisme guru (Febriani, n.d.).

\section{Kesimpulan}

Dalam rangka pelaksanaan supervisi maka harus mencakup semua komponen yang terkait dan mempengaruhi terhadap keberhasilan program supervisi. Supervisi merupakan kegiatan yang kompleks, oleh karena itu harus dilakukan oleh orang-orang profesional. Di dalam pengetian tersebut tergambar bahwa seorang supervisor harus orang yang memiliki jabatan resmi yang memiliki kewenangan atau otoritas dalam pengawasan

Sebagai salah satu sumber otoritas pelaksanaan supervisi oleh pengawas sekolah maka pengawas/supervisor memegang peranan yang sangat strategis dalam meningkatkan kualitas pembelajaran. Supervisi atau pembinaan tenaga pendidik oleh pengawas ini lebih menekankan pada pembinaan profesioanalisme yaitu pembinaan yang lebih ditujukan dalam upaya memperbaiki dan meningkatkan kemampuan profesionalisme guru

Pelaksanaan supervisi oleh pengawas sekolah mendasarkan prencanaan program yang telah disusun; meliputi tahap: persiapan, pelaksanaan, dan penilaian/ pelaporan.

Standar mutu pengawas yang telah ditetapkan oleh Direktorat Jenderal Peningkatan Mutu Pendidik dan Tenaga Kependidikan Direktorat Tenaga Kependidikan Departemen Pendidikan Nasional bahwa pengawas sekolah berfungsi sebagai supervisor baik supervisor akademik maupun supervisor manajerial.

\section{Bibliografi}

Amanda, M. O., Salam, R., \& Saggaf, S. (2017). Pengaruh Supervisi Kepala Sekolah Terhadap Kinerja Guru Di SMK Negeri 1 Bungoro Kabupaten Pangkep. Prosiding Seminar Nasional Himpunan Sarjana Ilmu-Ilmu Sosial, 2, 149154.Google Scholar

Febriani, A. L. (n.d.). Pelaksanaan Supervisi Akademik Pengawas Sekolah Sebagai Upaya Peningkatan Profesionalisme Guru. Google Scholar

Fitri, E. (2020). Konsep Dasar Supervisi Pendidikan. Google Scholar

Hendriawati, R. (2019). Supervisi pendidikan. Google Scholar

Husni, L. (2019). Pentingnya Penggunaan Supervisi Secara Efektif Dalam Pendidikan. Google Scholar

Kristiawan, M., Yuniarsih, Y., Fitria, H., \& Refika, N. (2019). Supervisi pendidikan. Bandung: Alfabeta. Google Scholar 
Messi, M., Sari, W. A., \& Murniyati, M. (2018). Pelaksanaan supervisi akademik pengawas sekolah sebagai upaya peningkatan profesionalisme guru. JMKSP (Jurnal Manajemen, Kepemimpinan, Dan Supervisi Pendidikan), 3(1), 114-125. Google Scholar

Musdalipa, M., Mustaming, M., Taqwa, T., \& Wiratman, A. (2021). Peranan Pengawas Dalam Meningkatkan Mutu Pengelolaan Sekolah Dasar. Jurnal Konsepsi, 10(2), 106-112. Google Scholar

Sabandi, A. (2013). Supervisi pendidikan untuk pengembangan profesionalitas guru berkelanjutan. Pedagogi: Jurnal Ilmu Pendidikan, 13(2), 1-9. Google Scholar

Slameto, S. (2016). Supervisi Pendidikan Oleh Pengawas Sekolah. Kelola: Jurnal Manajemen Pendidikan, 3(2), 192-206. Google Scholar

Sudjana, N. (2006). Standar Mutu Pengawas. Jakarta: Depdiknas. Google Scholar

\section{Copyright holder :}

Feri Uliya Candra (2020).

First publication right :

Action Research Literate

This article is licensed under:

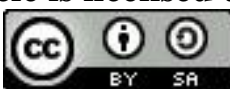

